\title{
A pedagogia crítica da educação física escolar: relatos de uma experiência docente com o badminton
}

\author{
Teaching Badminton at school: reports from a public school's pedagogical experience
}

\section{Samuel Nascimento de Araújo, Leandro Oliveira Rocha, Márcio Cardoso Coelho, Fabiano Bossle} Universidade Federal do Rio Grande do Sul (UFRGS), Porto Alegre/RS, Brasil

\section{HISTÓRICO DO ARTIGO \\ Recebido: 28 março 2020 \\ Revisado: 08 julho 2020 \\ Aprovado: 16 julho 2020}

\section{PALAVRAS-CHAVE:}

Pedagogia Crítica; Educação Física escolar; Badminton; Relato de

Experiência Docente.

\section{KEYWORDS:}

Critical Pedagogy; School Physica Education; Badminton; Teaching Experience Report.

\section{RESUMO}

INTRODUÇÃO: Este relato apresenta uma experiência pedagógica de ensino do badminton sustentada nas perspectivas de uma pedagogia crítica freiriana, visando superar limitações de ensino dos esportes em contextos escolares pautadas exclusivamente no aprimoramento técnico e na aptidão física, assim como potencializar a experimentação corporal dessa modalidade esportiva e a problematização de aspectos sociais, culturais e econômicos.

OBJETIVO: Apresentar uma prática pedagógicas de Badminton para discutir uma proposta pedagógica crítica da educação física escolar.

MÉTODOS: A realização desta prática pedagógica ocorreu com 68 estudantes de turmas de 8 ㅇ e 90 ano do Ensino Fundamental de duas escolas públicas, uma da área rural e outra urbana, do município de Guarani das Missões (RS), no ano de 2019, tendo como duração um trimestre letivo com 20 aulas.

RESULTADOS: Os estudantes vivenciaram a prática da modalidade de badminton, tendo nas rodas de conversa um excelente espaço de diálogos e reflexões críticas sobre aspectos históricos, econômicos e sociais que envolvem o badminton, políticas públicas de esporte e lazer do município e a cultura esportiva da região, marcada pela hegemonia do futsal e presença de uma monocultura esportiva na escola.

CONCLUSÃO: A prática do badminton potencializou a reflexão crítica sobre a cultura esportiva local e permitiu que os estudantes se colocassem no centro do processo educativo por meio do diálogo e reconhecessem a problematização do contexto social como possibilidade de "ser mais".

\section{ABSTRACT}

BACKGROUND: This report deals with a pedagogical experience of teaching sports - Badminton - in order to overcome the limitations of teaching sports in school contexts based on performance and aptitude, but that this can be a central element for the experience of the modality and also for the knowledge production that allows contextualization of the phenomenon with social, cultural and economic aspects, based on the perspective freed by Paulo Freire.

OBJECTIVE: Present a Badminton pedagogical practice to discuss a criticized pedagogical proposal School Physical Education.

METHODS: His pedagogical practice took place with 68 students from the 8th and 9th grades of elementary school in two public schools, one in the rural and the other in the city of Guarani das Missões (RS, Brazil), in 2019, with a duration of one academic quarter with 20 lessons.

RESULTS: The students experienced the practice of the badminton modality, having in the conversation circles an excellent space for dialogues and critical reflections on historical, economic and social aspects involving badminton, public policies of sport and leisure in the municipality and the sports culture of the region, marked by the hegemony of futsal and the presence of a sports monoculture at school.

CONCLUSION: The practice of badminton allowed students to place themselves at the center of the educational process through dialogue, which led to critical debates regarding the sports practices that circulate in the community, and also allowed students to recognize themselves as having the possibility of "being more". 


\section{INTRODUÇÃO}

Historicamente a educação física escolar foi balizada por perspectivas militares, médicas e desportivas, as quais, em geral, se sustentaram no conhecimento acadêmico de cunho biomédico, biodinâmico e fisiológico, e promoveram o ensino dos esportes no âmbito escolar reduzido ao treinamento de alto-rendimento, à competição esportiva e ao aprimoramento da aptidão física (CAPARRÓZ; BRACHT, 2007; BRACHT, 2010). Sob tais perspectivas, a prática pedagógica de professor de Educação Física permaneceu restrita à reprodução de normas e regras institucionalizadas, à testagem, classificação e estratificação de estudantes e à formação de equipes escolares de competição (CAPARRÓZ, 2007).

$\mathrm{Na}$ esteira dessa configuração inicial, ainda há indícios de que os imperativos do treinamento físico desportivo e a valorização da seleção de talentos esportivos justificam a manutenção de processos didáticos-pedagógicos prescritivos, avaliativos, meritocráticos e excludentes na escola. Por conseguinte, desconsiderando os avanços acadêmicos específicos da educação física escolar promovidos pelas ciências sociais, que primam pelo potencial educativo dos esportes quanto à formação crítica (CAPARROZ; BRACHT, 2007; BRACHT, 2010) e cultural (NEIRA, 2007) dos estudantes. Não é novo, e nem por acaso, que desde 1997 Caparróz (2007, p. 75) adverte sobre a dicotomia entre a Educação Física "na" escola e a "da" escola com o intuito de romper com a influência histórica das instituições militar, médica e desportiva e, em contraponto, defender que "a Educação Física existe de fato na escola" e que, no âmbito escolar, ela incorpora a preocupação com tudo aquilo que o homem faz e pensa sobre corpo e movimento, isto é, o estudo da cultura corporal com ênfase nas experimentações corporais diversas e na discussão sobre seus significados e representações sociais.

Naturalmente a proposta de ensino dos esportes nas escolas é elaborada e desenvolvida segundo perspectivas teórico-metodológicas assumidas pelo professor de Educação Física, que ora seleciona modalidades esportivas com base na sua experiência pessoal ou no gosto e interesse dos estudantes e, em outros momentos, busca atender demandas institucionais, como selecionar estudantes habilidosos técnica e fisicamente para compor equipes esportivas que representarão a escola em jogos escolares - eventos competitivos entre escolas que confirmam resquícios do modelo esportivizado de Educação Física que ainda se mantem hegemônico quando se trata do objetivo do ensino dos esporte na escola (ARAÚJO, 2016; ARAÚJO, ROCHA, BOSSLE, 2018). Todavia, se for restrita às influências acadêmicas de perspectivas biomédicas e fisiológicas, a Educação Física corre o risco de continuar a não ser compreendida como área dotada de um conhecimento específico, "como um saber de referência, e, sim, apenas no tocante aos serviços prestados à manutenção do status quo, [...] pensada e implementada somente em virtude de se estabelecer como um valioso instrumento de difusão e inculcação de valores da elite" (CAPARRÓZ, 2007, p. 121-2, grifo do autor).

Nesse sentido, a mera inserção do esporte na escola não é suficiente, pois foi potencializada na década de 1970 e "indica a subordinação da educação física aos códigos/sentido da instituição esportiva", caracterizando-se como um prolongamento da instituição esportiva e promovendo "princípios de rendimento atlético/desportivo, competição, comparação de rendimentos e recordes, regulamentação rígida, sucesso no esporte como sinônimo de vitória, racionalização de mios e técnicas etc." (SOARES et al, 1992, p. 54).

Com isso, queremos salientar que, independentemente das diversas possibilidades didáticas assumidas pelos professores e dos objetivos institucionais que por vezes se sobrepõem à política educativa, é fundamental valorizar e reconhecer o conhecimento produzido na escola e os princípios educacionais que legitimam da Educação Física como componente curricular. Conforme identificado por Coelho e Rocha (2019), a própria legitimidade da Educação Física na escola continua sendo impactada por perspectivas reducionistas que embaçam uma visão mais clara do tempo e o lugar da Educação Física escolar, qual seja, o momento áulico na escola, no qual professores e estudantes compartilham a construção coletiva de conhecimentos (COELHO; ROCHA, 2019). Sobre esse aspecto, cabe citar:

Em retorno à discussão que propomos, talvez a ideia de haver um "não lugar" da Educação Física escolar esteja muito mais associada ao distanciamento acadêmico do conhecimento produzido na escola, com os estudantes, assim como da reflexão sobre a complexidade dos contextos escolares e as possibilidades de pensar e materializar prática educativas contrahegemônicas. Entender que a escola também é um lócus de produção e construção de conhecimento é fundamental porque a problematização da própria prática docente adquire condições de (re) significar o conhecimento acadêmico com apontamentos empíricos produzidos no "chão da escola". Há um saber que é construído na escola e que não será compreendido sem o esforço de estar na escola e entender que os docentes o produzem em processos de ação-reflexão-ação, localiza a noção de uma epistemologia da prática (COELHO; ROCHA, 2019, p. 19).

Nesse sentido, para além de limitações didático-pedagógica tecnicistas e esportivizadas, o esporte como manifestação da cultura corporal é extremamente relevante no processo de ensino crítico-reflexivo, haja vista que a discussão contextualiza do fenômeno esportivo permite abranger as suas dimensões culturais, políticas e econômicas. Isso significa que não se trata de negar ou silenciar as discussões sobre treinamento técnico, esportes institucionalizados ou aprimoramento fisiológico pelo exercício, mas sim, contrapor e substituir o entendimento da aula de Educação Física como espaço de treinamento esportivo pelo de experimentação corporal e reflexões crítica. Pois, na escola:

[...] a Educação Física seria definida como prática pedagógica que, no âmbito escolar, seleciona e tematiza determinados elementos da produção sociocultural da nossa sociedade, ou seja, seus conteúdos de ensino são as atividades expressivas corporais, como jogo, esporte, dança, ginastica, luta entre outros (GARIGLIO, 2013, p. 17).

Também não basta substituir o treinamento de uma modalidade esportiva por outra, uma vez que é vital repensar o processo didático-pedagógico e seus princípios formativos. Por isso a simples inclusão de outras modalidades esportivas, como o badminton - que ilustra a experiência docente apresentada neste texto -, não é suficiente para promover práticas pedagógicas condizentes com o projeto utópico de uma sociedade transformada, o qual exige interativamente e participação ativa dos estudantes, como foi considerado por Molina Neto (1996, p. 62) há mais de vinte anos:

O esporte na escola deve ser trabalhado tendo como horizonte a expressão do aluno e à luz de uma metodologia diferenciada, à medida que o mesmo é, acima de tudo, um instrumento a mais de educação, cujo objetivo maior deve ser, além da capacidade de comunicação e expressão do estudante, o de desenvolver a autonomia. 
Logo, também há importantes possibilidades de materializa pedagogias críticas capazes de romper com a reprodução de desigualdades e injustiças sociais historicamente produzidas com a invasão cultural, também existente no contexto cultural esportivo (KUNZ, 2001) e presente na padronização e colonização do conhecimento escolar (SANTOMÉ, 2013). Dito de outro modo, ampliar prática pedagógica do esporte com a reflexão crítica permite identificar contradições importantes para posicionar a denúncia e resistência a discursos e práticas pedagógicas excludentes e opressoras que permeiam metodologias de ensino da Educação Física na escola que se valem de uma educação bancária (FREIRE, 1987). Assim como adverte Bossle (2018, p. 27), é fundamental reafirmar a "práxis educativa política e vice-versa" e posicionar o professor de Educação Física como intelectual transformador e sua prática pedagógica como "inédito viável".

Sendo assim, diante destas reflexões introdutórias, apresentaremos neste texto uma experiência docente com o badminton, construída com estudantes do Ensino Fundamental de duas escolas do município de Guarani das Missões (RS), para discutir sobre alguns elementos didáticos que integram uma proposta pedagógica crítica de inspiração freiriana na Educação Física escolar entendendo a emergência de uma perspectiva crítica da Educação Física escolar

\section{MÉTODOS}

Este estudo, de abordagem qualitativa, foi elaborado a partir do relato de experiência docente realizada com estudantes do ensino fundamental de duas escolas pública localizadas no município de Guarani das Missões (RS). Ambas as escolas compartilham a mesma cultura local, sendo que uma pertence à rede municipal de ensino, está localizada na zona rural e abriga filhos de pequenos agricultores e de trabalhadores em propriedades rurais; enquanto que a outra escola pertence à rede estadual de ensino, está localizada na zona urbana do município e abriga estudantes que residem na periferia da cidade, com alguns oriundos da área central e outros da área rural.

A prática docente, realizada em nas turmas de 8 ㅇ e 90 de uma escola da rede municipal e de uma escola da rede estadual, contou com a participação total de 68 estudantes e foi desenvolvida durante um trimestre letivo, compreendendo o total de 20 aulas em cada turma e assim organização (Quadro 1).

Conforme apresentado na organização das aulas e discussões subsequentes, as rodas de conversa durante as duas primeira aulas foram decisivas para os estudantes estabelecerem os caminhos que iriam percorrer ao longo das aulas, avançando o estudo do badminton na escola do mero aprendizado e treinamento de gestos técnicos para discussões temáticas que permitem estabelecer a reflexão crítica sobre cultura, sociedade, política e economia. Pautadas nas experimentações corporais e nos diálogos subsequentes, as aulas ganharam maior adesão dos estudantes, os quais, sedentos por saber mais, foram atuantes na construção e no compartilhamento de nos conhecimentos.

Sendo assim, as discussões didático-pedagógicas que compõem este texto são originárias dessa experiência docente com o badminton no ensino fundamental, a qual foi registrada nos planos de aulas, diários de classe, registros pessoais do professor e utilizada para ilustrar uma prática pedagógica crítica da educação física escolar.
Quadro 1. Cronograma das aulas realizadas.

\begin{tabular}{|c|c|}
\hline Aula & Descrição das temáticas das aulas \\
\hline 01 e 02 & $\begin{array}{l}\text { - Escolha da modalidade esportiva para ser estudada em diálogo com } \\
\text { os estudantes; } \\
\text { - Mapeamento dos conhecimentos dos estudantes sobre a mesma. }\end{array}$ \\
\hline 03 a 06 & $\begin{array}{l}\text { - Revisão histórica da modalidade esportiva; } \\
\text { - Primeiro contato com os implementos e a gestualidade própria do } \\
\text { jogo. }\end{array}$ \\
\hline 07 a 14 & $\begin{array}{l}\text { - Experimentação corporal do badminton quanto aos gestos técnicos } \\
\text { básicos da modalidade; } \\
\text { - Diálogo sobre a cultura esportiva e as modalidades esportivas hegemô- } \\
\text { nicas na comunidade; } \\
\text { - Reflexão sobre a invisibilização da diversidade de modalidades espor- } \\
\text { tivas existentes e os imperativos da lógica de mercado e consumo na } \\
\text { promoção de algumas modalidades; } \\
\text { - Preconceito social visíveis nas relações de gênero e etnia no contexto } \\
\text { esportivo; - As políticas públicas de esporte e lazer do município; } \\
\text { - Incentivos financeiros realizados em outros países para a massificação } \\
\text { do badminton. }\end{array}$ \\
\hline 15 e 16 & $\begin{array}{l}\text { - Levantamento de dúvidas e organização de perguntas sobre a gestão } \\
\text { do esporte } \\
\text { - Contato e diálogo na Secretaria Municipal de Educação, Cultura, } \\
\text { Esporte e Lazer. }\end{array}$ \\
\hline 17 e 18 & $\begin{array}{l}\text { - Análise e síntese do diálogo com o responsável pela promoção do } \\
\text { esporte no município, } \\
\text { - Elaboração de resenhas críticas sobre os esportes que integram } \\
\text { a cultura escolar e produção artística (em desenho) para ilustrar o } \\
\text { badminton. }\end{array}$ \\
\hline 19 e 20 & $\begin{array}{l}\text { - Realização de uma Mostra Pedagógica para socializar as produções } \\
\text { textuais e artísticas para os demais estudantes da escola. }\end{array}$ \\
\hline
\end{tabular}

Fonte: Elaborada pelos autores com base nos diários de classe.

\section{RESULTADOS}

Para compreender o badminton na escola e, ao mesmo tempo, identificar a discussão acadêmica sobre o badminton, realizamos uma busca por publicações que tratam, especificamente, o badminton na educação física escolar. Na primeira, o Portal de Periódicos da Coordenação de Aperfeiçoamento do Pessoal de Nível Superior (CAPES), identificamos nove estudos e selecionamos três para análise, são eles: "Badminton: possibilidades de ensino aplicadas ao contexto da educação física escolar" (ABURACHID et al., 2019), publicado no Journal of Physical Education; "Entre o lance e a chance: lógica interna numa final de badminton" (GOMES-DA-SILVA; SOUSA-CRUZ; ARRUDA, 2019), publicado na revista Motrivivência; e "Perfil nutricional e ingestão alimentar de cálcio e ferro por atletas adolescentes praticantes de badminton" (DOS SANTOS; SANTOS; CARVALHO, 2017), publicado na Revista Brasileira de Nutrição Esportiva.

A segunda, no periódico Cadernos de Educação Física e Esporte encontramos os trabalhos: "Transformação didático-pedagógica e o ensino de novos esportes no Ensino Médio" (SÁ; MYSKIW, 2009), "O ensino dos esportes de raquete no ambiente escolar" (CORRÊA; FREITAS; SILVA, 2019) e "Esportes de raquete, divulgação e infraestrutura: influências sobre a prática" (MACHADO; SOUZA; SILVA, 2019).

Ao realizar a busca, chama atenção a escassez de pesquisas que discutem o badminton na escola, o que talvez seja em função da pouca visibilidade desta modalidade esportiva em comparação a outras, que apresentam maior destaque nos meios de comunicação e no contexto social. Tal como evidenciam por Machado, Souza e Silva (2019), modalidades esportivas como o futebol, o voleibol, o handebol e o basquete, em geral são reconhecidas socialmente, valorizadas pelos professores e, sendo 
assim, predominantes nas aulas de Educação Física. Por conseguinte, o badminton ainda aparece timidamente na escola devido à supervalorização de algumas modalidades esportivas e à fatores que dificultam a sua implementação prática, tais como: o pouco conhecimento dos professores sobre a modalidade, a necessidade de espaços físicos adequados para a experimentação corporal e a falta de recursos financeiros para adquirir raquetes e petecas (MACHADO; SOUZA; SILVA, 2019). Diante desse cenário, os autores supracitados reforçam a valorização das diversas modalidades esportivas e enfatizam que a inserção do badminton nas aulas de Educação Física alavanca outras aprendizagens e amplia a discussão sobre a pedagogia dos esportes, principalmente porque desperta a motivação e o interesse dos estudantes pela prática de esportes de raquetes (MACHADO; SOUZA; SILVA, 2019).

De modo semelhante, Aburachid et al. (2019) destacam a potencialidade formativa do badminton na Educação Física escolar, mas advertem sobre a necessidade de analisar as diferentes concepções metodológicas de ensino sob o risco de manter uma proposta pedagógica ao ensino de gestos técnicos. Nesse caso, embora muitos professores tenham superado a utilização de metodologias de ensino tradicionais - marcadas pela prática de uma modalidade esportiva com a mera finalidade de realizar uma atividade física durante a aula -, ainda há processos pedagógicos restritos ao "saber fazer", centrados em objetivos procedimentais que focam o aprimoramento técnico ou de habilidades física específicas da modalidade esportiva desenvolvida (ABURACHID et al., 2019). Por isso Aburachid et al. (2019) sugerem analisar cuidadosamente os diferentes aportes metodológicos de ensino para não reproduzir propostas educativas restritas à mera formação de atletas nem limitadas a conteúdos atitudinais, isto é, somente direcionadas à formação de valores humanos, mas sem qualquer referência com perspectivas crítica e engajadas com a transformação social.

Por sua vez, Corrêa, Freitas e Silva (2019) lembram que a inserção de outras práticas corporais nas aulas também gera resistência por parte de estudantes que tentem a boicotar as modalidades esportivas que não conhecem. Depois de analisar a inserção dos esportes de raquetes na Educação Física através da observação de vinte aulas realizadas em turmas de 7ํ Ano e 8 Ano do Ensino Fundamental, os autores reiteram a possibilidade de confeccionar raquetes e a persistência frente às adversidades para superar a rejeição inicial dos estudantes em realizar as atividades, pois, conforme identificaram, a tendência é que as práticas corporais desconhecidas se tornem gradativamente interessante ao longo das aulas (CORRÊA; FREITAS; SILVA, 2019). Trata-se de considerações semelhantes às de Sá e Myskiw (2009), que abordam a prática do badminton na escola com intuito de apresentar alternativas de ensino mediante a reprodução das mesmas modalidades esportivas historicamente contempladas na Educação Física, sobretudo o futebol. Em contraponto ao saber-fazer, os autores endossam a reflexão dos aspectos socioculturais e da relação entre o esporte e seus significados sociais para promover a compreender o fenômeno esportivo.

De fato, os argumentos presentes nos estudos revisados são coesos e legítimos, ainda mais se relacionarmos com a nossa experiência docente em escolas públicas - sobretudo localizadas em comunidades escolares compostas por famílias com renda financeira mais baixa e, algumas, em situação de extrema pobreza -, cuja falta de equipamentos adequados e acesso às diversas práticas corporais esportivas inviabilizam a inserção do badminton na escola. Porém, o aspecto mais preocupante é a presença de uma possível lacuna na formação acadêmica dos professores, que demarca uma formação técnico-instrumental e, na escola, favorece a reprodução das mesmas práticas corporais esportivas circunscritas na cultura local, evidenciando a presença de uma "monocultura esportiva" pautada nos esportes coletivos historicamente privilegiados nas aulas de Educação Física (ARAúJO, 2016, p. 134).

Pensando assim, entendemos que os estudos selecionados através da busca nos periódicos da Educação Física endossam a elaboração deste texto, fruto da experiência docente com o badminton na escola. Não obstante, justificam a proposta de apresentar práticas pedagógicas que superam perspectivas de ensino tecnicistas com a materialização de uma pedagogia crítica da Educação Física, na qual o professor assume autoria dos processos educativos e promove um ensino crítico-reflexivo (CAPARRÓZ; BRACHT, 2007) - a qual apresentamos a seguir.

\section{Uma pedagogia crítica para o ensino do badminton nas aulas de Educação Física Escolar}

O contexto das duas escolas onde realizamos a experiência docente e marcado pela competição de esportes coletivos, em especial o futsal e o voleibol. Semelhante ao treinamento de categorias de base de clubes esportivos, por vezes a aula de Educação Física visa a detecção de talentos esportivos e o alto rendimento, constituindo-se em uma espécie de "fábrica de campeões", legitimada pela própria equipe diretiva da escola, que supervaloriza a vitória das equipes esportivas nos jogos escolares e, por isso, cobra resultados dos professores de Educação Física nas competições municipais e regionais. Não há como negar, para a escola a vitória das equipes esportivas é mais do que motivo de orgulho e reconhecimento pelo trabalho qualificado do professor ou empenho dos estudantes, é sinônimo de status social na região, oriundo da comparação direta com as demais escolas.

Para romper com esse modelo de ensino reduzido ao treinamento esportivo visando o alto-rendimento, nos últimos anos de trabalho na escola procuramos incluir outras práticas corporais nas aulas de educação física e, principalmente, materializar uma pedagogia crítica capaz de potencializar a reflexão e a problematização da cultura corporal. Para isso, desenvolvemos diversas práticas corporais, como: jogos cooperativos e populares, judô, frevo, danças gaúchas e de salão, ginástica para todos, trilhas na natureza, escaladas e rapel, ciclismo urbano e rural e corridas e caminhadas de orientação com mapas elaborados pelos próprios estudantes. No que se refere aos esportes, problematizamos as diversas modalidades esportivas existentes, reelaboramos as regras oficiais dos esportes já conhecidos e inserimos modalidades nunca praticadas, como o hóquei indoor, o tchoukball, o futebol americano, o goalbol e badminton - cuja prática pedagógica pauta a discussão a seguir.

De modo geral, as aulas foram organizadas em uma rotina composta por três momentos complementares: a roda de conversa inicial, para identificar problematizações e retomar aspectos tratados nas aulas anteriores; as experiências coletivas, planejadas e compartilhadas pelos estudantes e voltadas para a 
proposta específica da aula; e a roda de conversa final, para retomar a problematização inicial e realizar o fechamento da aula com destaques e discussões pontuais sobre o assunto tratado. Sob essa organização, o badminton foi inserido com o intuito de estudar os esportes de raquetes e sem contato físico direto, problematizar a cultura esportiva presente à educação física escolar e no município de Guarani das Missões (RS) e analisar a possibilidade de inserir outras práticas esportivas em espaços comunitários.

Para dar conta desta tarefa, pautamos a sequência pedagógica na seguinte problematização: "Por que o badminton não é conhecido como prática esportiva nos contextos de periferia?". Ao longo das aulas, realizamos seminários e debates sobre os seguintes temas: o esporte na escola, o badminton e a falta de incentivo do poder público e as políticas públicas de esporte e lazer do município; a partir dos quais os estudantes produziram textos e desenhos para identificar as reflexões e ilustrar as aulas de badminton.

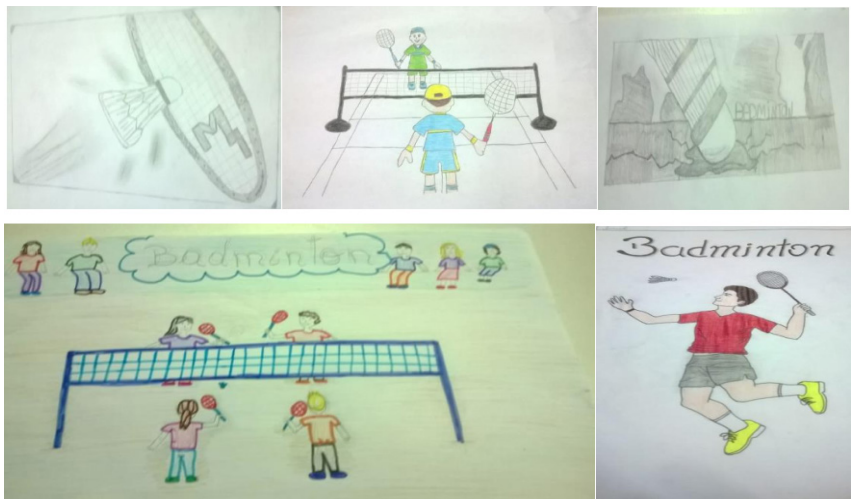

Figura 1. imagens das produções artísticas de badminton dos estudantes.

No que diz respeito às experimentações corporais com utilização das raquetes e do jogo de badminton, os estudantes enfrentavam as dificuldades técnicas e táticas com soluções criativas, que gradativamente os levavam a dominando as formas básicas de se movimentar e organizar em quadra. Dessa forma, os estudantes não eram obrigados a adotar ou reproduzir movimentos padronizados nem ser cobrados por erros táticos, como geralmente ocorre no treinamento de alto-rendimento. É importante salientar que inicialmente discutimos sobre jogos e brincadeiras com petecas confeccionadas de sabugo de milho e penas de aves, que eram realizadas na comunidade e agora não são mais praticadas, confeccionamos as petecas durante as aulas e jogamos sem raquetes, utilizando somente as palmas das mãos.

Assim, a prática do badminton era construída através de experimentações corporais que integravam a vivência dos equipamentos e a elaboração de desafios pessoais, disputas em duplas e pequenos grupos e jogos com regras pré-estabelecidas; sendo que, ao longo da prática, os gestos técnicos de rebater e as estratégias e posicionamentos táticos de jogo eram identificadas e exploradas.

Primeiramente foram confeccionadas petecas confecciona- das com EVA, simulando brincadeiras com a utilização das mãos, sem raquetes, e posteriormente a utilização de raquetes de madeira. Após esta aproximação, foi realizada a experimentação de raquetes e petecas específicas para a prática do Badminton.

Ao mesmo tempo em que as experimentações corporais ampliavam a compreensão dos estudantes sobre as aulas de Educação Física - antes restrita ao aprendizado de ações motoras e modos institucionalizados de jogar - os diálogos sobre a origem, a história e a prática do badminton no contexto mundial, nacional e local permitiam estabelecer críticas sobre aspectos socias, econômicos e políticos. Nesse caso, semelhante a Maldonado e Nogueira (2020), utilizamos as rodas de conversas como espaços de problematização das experimentações corporais de badminton compartilhadas em aula, inclusive no que se refere a sua gestualidade, características do jogo, dificuldades de manusear a raquete e de rebater com precisão. Assim, de modo colaborativo, os estudantes assumiam protagonismo nos debates e na construção de gestos e estratégias mais eficientes de manter a peteca no ar, convergindo com o pensamento de Bracht (2010), segundo o qual o aprendizado de uma modalidade esportiva não está somente relacionado à reprodução de regras institucionalizadas e ações motoras determinadas, pois envolve também a compreensão de procedimentos de adaptação do jogo, a elaboração e organização de estratégias coletivas e o entendimento de sua relação com a vida em sociedade.

Dessa forma, provocamos os estudantes a analisar quais são as modalidades esportivas presentes no contexto escolar e quais são compartilhadas na comunidade local e da região das Missões. Somente depois de estabelecer relações entre a cultura esportiva regional e da escola dialogamos sobre a representatividade dos eventos esportivos no município e o modo como estes são reproduzidos e valorizados sobretudo entre a população masculina. Isso não significa que as mulheres não gostem ou não pratiquem esportes nessa região, mas sim, que a visibilidade e o incentivo financeiro à competição esportiva de futsal estão condicionados aos interesses do público masculino e em acordo com atitudes chauvinistas, diretamente relacionadas ao sexo masculino e perceptíveis na noção de competição esportiva como um combate, uma guerra, uma demonstração de virilidade, agressividade e força. Assim, diálogos como esses permitiram discutir questões ligadas ao machismo estrutural presente em nossa sociedade e a urgência de reconhecer a mulher no cenário esportivo; bem como identificar o racismo presente no contexto esportivo e relacioná-lo com as diversas formas de preconceitos que permeiam a organização social da comunidade que habita o município.

Relacionar os contextos macrossocial e microssocial durante os diálogos foi decisivo para identificarmos a estrutura física e os equipamentos necessários para a prática do badminton e analisarmos os espaços públicos e as modalidades esportivas possíveis de serem praticadas no município. Por conseguinte, os próprios estudantes compararam os gastos necessários para promover o badminton com os recursos públicos despendidos para a prática do futebol e colocaram em xeque os investimentos públicos destinados para o esporte e o lazer. Naturalmente, ficamos com muitas dúvidas sobre as decisões políticas e econômicas municipais na área dos esportes e, para saná-las, entramos em contato a Secretaria Municipal de Educação, Cultura, Esporte e Lazer de Guarani das Missões (SMEC-GM) para conversar com o responsável pelo departamento do esporte e lazer. 
Para nossa infeliz surpresa, a SMEC/GM não possuía uma pessoa responsável ou especificamente habilitada para planejar e administrar a pasta do esporte e lazer, somente um funcionário com o cargo de chefia (C.C. ${ }^{1}$ ) na coordenação do Conselho Municipal de Desportos (CMD), órgão responsável pela organização e realização de eventos e campeonatos esportivos municipais. Logo, por meio do diálogo junto à SMEC-GM, ficou evidente que a falta de espaços públicos adequados para as práticas esportivas e de oportunidade para que as pessoas da comunidade conheçam e pratiquem outras modalidades esportivas está relacionada com o fato dos recursos financeiros públicos serem destinados estritamente às competições esportivas, sem que haja qualquer projeto ou proposta política voltada para o esporte no âmbito do lazer.

Para esclarecer melhor como eram as discussões, nas rodas de conversa sobre o badminton e a organização em classes sociais relacionamos a inviabilidade de praticar a modalidade nas escolas de comunidades mais pobres, cuja dificuldade de acesso aos materiais e equipamentos necessário impede o acesso às diversas modalidades esportivas por grande parte população que estuda nas escolas públicas. Nesse diálogo, os estudantes disseram que as pessoas que vivem nas periferias parecem invisíveis aos olhos da sociedade e do poder público, sendo que uma aluna questionou: "Professor, achas que irão investir em material para as pessoas que moram na vila? Se irão colocar coisa boa não vai ser pra nós".

Percebemos que esta fala revela a posição dos estudantes frente às formas de opressão vividas no local e demonstra que há indícios de uma tomada de consciência que produz resistência à dominação. Ademais, evidencia o desinvestimento do poder público local com as pessoas menos favorecidas da comunidade, materializado na falta de acesso às práticas esportivas, de materiais didáticos para estudar as diversas modalidades esportivas e se encaminhando a outros segmentos que envolvem os bens sociais e culturais que são de difícil acesso para quem não pode pagar. Por isso a necessidade de um olhar crítico frente às políticas públicas de esporte e lazer no município com vistas à promoção de mudanças paradigmáticas.

Esta busca por mudanças, que almeja uma conjuntura social justa e ética, na qual os grupos populares sejam escutados e tenham oportunidades de acesso à educação de qualidade e ao patrimônio imaterial cultural, também pressupõe a implicação do professor de escola pública com a transformação social. Somente quanto o professor está incomodado com a precarização e desumanização da educação e da vida de homens e mulheres que são vítimas da dominação e do controle historicamente produzidos, é que assume o seu posicionamento político na sociedade, entende que nunca é neutro e compreende o que é agir como intelectual transformador (FREIRE, 2000; GIROUX, 1997). Logo, também compreende a potencialidade da reflexão crítica nas aulas de Educação Física escolar, pois entende que somente a partir da prática problematizadora os educandos vão "desenvolvendo o seu poder de captação e de compreensão do mundo que lhes parece, em suas relações com ele, não mais como uma realidade estática, mas como uma realidade em

${ }^{1} \mathrm{CC}$ (Cargo de Chefia): estes cargos de chefia são cargos comissionados, em que a administração municipal utiliza ou para suprir a necessidade de tal cargo, ou no caso específico de comunidades de pequeno porte e conservadoras, para manter o grupo que compõe a coligação partidária a fim de manter as alianças para futuros pleitos municipais. transformação, em processo" (FREIRE, 1987, p. 71)

Pensando assim, a organização das aulas a partir de tematizações e problematizações sobre o badminton alavancaram discussões conceituais e de significados culturais, bem como reflexões sobre sentidos atribuído pelos estudantes às tarefas realizadas durante as aulas, como as experimentações corporais, as rodas de conversa, as pesquisas e a busca por informações junto à representantes da comunidade - como ocorreu no diálogo com a SMEC/GM. Cremos que assim, quando há inclusão de outras práticas corporais nas aulas e problematizações contextualizadas, é possível potencializar a curiosidade científica e a tomada de consciência dos estudantes, constituindo a maneira de materializar uma pedagogia crítica da Educação Física.

Deste modo, entendemos que o ensino do badminton nestas escolas permitiu identificar o potencial educativo do professor de Educação Física que, à luz de um olhar com inspiração freiriana, prima pela conscientização e emancipação dos estudantes. Mais do que mero treinador e/ou preparador físico que atende à demanda de formar atletas e equipes esportivas competitivas e vencedoras, o professor de Educação Física se engaja na luta de resistência dos oprimidos, dos marginalizados, pois concretiza a possibilidade dos estudantes analisar criticamente o contexto social, considerando aspectos históricos, políticos e econômico e, aos poucos, vivenciado a capacidade humana de "ser mais" (FREIRE, 1987).

\section{CONCLUSÃO}

Retomando nosso objetivo de apresentar uma experiência docente de Badminton pautada numa perspectiva crítica da Educação Física escolar, entendendo que é no diálogo que o homem se encontra com o mundo e constrói sua liberdade transformação social, destacamos a importância de entendermos o outro como outro e respeitarmos sua cultura, assim fica sob o oprimido a tarefa de ganhar força de transformação, pois "a organização das massas populares em classe é o processo no qual a liderança revolucionara, tão proibida quanto este, do dizer sua palavra, instaura o aprendizado da pronuncia de um mundo, aprendizado de mundo, aprendizado verdadeiro por isso dialógico" (FREIRE, 1987, p. 103).

Deste modo, estabelecemos uma relação pautada no diálogo crítico da realidade que estamos inseridos, professor e estudantes, e este movimento nos levou a pensar e compreender como as relações de poder se manifestam, e como não nos damos conta da dominação.

Assim, esse relato de experiência docente apresenta uma perspectiva de estudar o badminton no contexto escolar, nosso olhar para tratar o ensino da modalidade foi na contramão ao que a literatura encontrada na revisão apontou, para um olhar ainda pautado no rendimento, na melhor performance e na formação de atletas mesmo no contexto escolar. Entendemos que o badminton permite identificar a monocultura esportivas que é corroborada pelo poder público, e as limitações de sua inserção no contexto de escolas públicas, devido à falta de investimento e recursos, mas isso não torna impossível o tratamento da modalidade e a produção de conhecimento que esta permite.

Destacamos a potencialidade da roda de conversa que nos permitiu refletir sobre a nossa vida, nosso cotidiano a partir da experiência pedagógica com a modalidade esportiva 'badmin- 
ton', assim como encaminhou para a reflexão de temas que muitas vezes passam despercebidos nos contextos escolares, sobretudo quanto à reflexão sobre contextos sociais, que integra uma pedagogia crítica de perspectiva freiriana, pela qual, entendemos, condiciona as bases teóricas que potencializam a transformação social. Entendemos assim porque o processo de emancipação é coletivo e sustentado na atitude crítica que revela uma visão de mundo que não é mais ingênua, sobretudo quanto à própria conjuntura político-social vivida, algo que está alicerçado no reconhecimento do próprio lugar no mundo e das possibilidades de "ser mais". Afinal, como "os homens se educam em comunhão mediatizados pelo mundo" (FREIRE, 1987, p. 69), e esse princípio conduziu as aulas de Educação Física que desenvolvemos, também reafirmarmos nossa condição de intelectuais transformadores e localizamos nossa prática pedagógica como um inédito viável.

\section{REFERÊNCIAS}

ABURACHID, L. M. C.; DA SILVA, S. R. da; ARAÚJO, N. D.; GRECO, P. J. Badminton: possibilidades de ensino aplicadas ao contexto da educação física escolar. Journal of Physical Education, Maringá, v. 30, n. 1, p. 3055, 18 Jun. 2019.

ARAÚJO, S. N. de. Cultura Corporal de movimento na escola e cultura corporal de movimento da escola: uma etnografia sobre a particularidade da seleção de conteúdos de ensino da educação física escolar. 2016. 199f. Dissertação (Mestrado em Educação Física) - Universidade Federal do Rio Grande do Sul, Porto Alegre, 2016.

ARAÚJO, S. N. de. ROCHA, L. O.; BOSSLE, F. Sobre a monocultura esportiva no ensino da educação física na escola. Pensar a Prática, Goiânia, v. 21, n. 4, p. $842-35,2018$

BOSSLE, F. Nosso "inédito viável": professor de Educação Física intelectual transformador. In: MALDONADO, D. T.; NOGUEIRA, V. A.; FARIAS, U. S. Os professores como intelectuais: novas perspectivas didático-pedagógicas na educação física escolar brasileira. Curitiba: CRV, 2018.

BOSSLE, F.; BOSSLE, C. B. "O conhecimento de quem é mais valioso?" Educação Física Escolar, educação crítica e pesquisa científica no grupo DIMEEF/UFGRS. In: BOSSLE, F. Educação física escolar, etnografias e autoetnografias: a formação de intelectuais transformadores. Curitiba: CRV, 2018. p. 15-32.

BRACHT, V. A educação física no ensino fundamental. In: I Seminário Nacional: Currículo em Movimento - Perspectivas atuais. Anais... Belo Horizonte, 2010. p. 21-31.

CAPARRÓZ, F. E. Entre a educação física na escola e a educação física da escola: e educação física como componente curricular. 2. ed. Campinas: Autores Associados, 2007.

CAPARRÓZ, F. E.; BRACHT, V. O tempo e o lugar de uma didática da educação física. Revista Brasileira de Ciências do Esporte, Campinas, v. 28, n. 2, p. 21-37, jan. 2007.

COELHO, M. C.; ROCHA, L. O. O nosso "inédito viável": diálogos sobre o lugar da educação física escolar. Revista Brasileira de Educação Física Escolar, São Paulo, v. 5, v. 2, p. 8-21, 2019

CORRÊA, M. M. L.; FREITAS, T. C. R.; SILVA, S. A. da. O ensino dos esportes de raquete no ambiente escolar. Caderno de Educação Física e Esporte, Marechal Cândido Rondon, v. 17, n. 1, p. 309-16, 2019.

FREIRE, P. Educação e mudança. 37. ed. São Paulo: Paz e Terra, 2016.

FREIRE, P. Pedagogia da Indignação: cartas pedagógicas e outros escritos. São Paulo: UNESP, 2000.

FREIRE, P. Pedagogia do Oprimido. 11. ed. Rio de Janeiro: Paz e Terra, 1987.

GARIGLIO, J. A. fazeres e saberes pedagógicos de professores de Educação Física. ljuí: Unijuí, 2013

GOMES-DA-SILVA, P. N.; SOUSA-CRUZ, R. W. de; ARRUDA, E. P. de S. Entre o lance e a chance: lógica interna numa final de badminton. Motrivivência, Florianópolis, v. 31, n. 58, p. 1-19, 2019.

KUNZ, E. Transformação didático-pedagógico do esporte. 4. ed. ljuí: Unijuí, 2004.

MACHADO, M. A. de O.; SOUZA, R. R. de; SILVA, S. A. da. Esportes de raquete, motivação, divulgação e infraestrutura: influências sobre a prática. Caderno de Educação Física e Esporte, Marechal Cândido Rondon, v. 17, n. 2, p. 177-183, 2019.

MALDONADO, D. T.; NOGUEIRA, V. A. Educação física no ensino médio: experiências educativas inspiradas pelos ensinamentos freireanos. Caderno de Educação Física e Esporte, Marechal Cândido Rondon, v. 18, n. 1, p. 4954, 2020.

NEIRA, M. G. Ensino de educação física. São Paulo: Thomson Learning, 2007

SÁ, J. J. de.; MYSKIW, M. Transformação didático-pedagógica e o ensino de novos esportes no ensino médio: um relato de experiência. Caderno de Educação Física: Estudos e Reflexões, Marechal Cândido Rondon, v. 8 n. 14, p. $85-93,2009$

SANTOMÉ, J. T. Currículo escolar e justiça social: o cavalo de tróia da educação. Porto Alegre: Penso, 2013.

SANTOS, D. A. dos; SANTOS, F. B. L. dos; CARVALho, L. M. F. de. Perfil nutricional e ingestão alimentar de cálcio e ferro por atletas adolescentes praticantes de badminton. Revista Brasileira de Nutrição Esportiva, São Paulo, v. 11, n. 63, p. 278-88, 2017.

SOARES, C. L.; TAFFAREL, C. N. Z.; VARJAL, E.; CASTELLANI FILHO, L; ESCOBAR, M. O.; BRACHT, V. Metodologia do ensino de educação física. São Paulo: Cortez, 1992

SOUZA, A. A. de. RAASCH; R. N. H.; MARIA, A. L. Badminton: um diferencia nas aulas de educação física escolar. Acta Brasileira do Movimento Humano, Ji-Paraná, v. 7, n. 3, p. 28-38, 2017.

\section{CONFLITO DE INTERESSE}

Os autores do estudo declaram não haver conflito de interesses.

\section{FINANCIAMENTO}

Este estudo não teve apoio financeiro.

\section{ORCID E E-MAIL DOS AUTORES}

Samuel Nascimento de Araújo (Autor Correspondente)

ORCID: 0000-0003-3601-0617.

E-mail: araujoedf@hotmail.com

Leandro Oliveira Rocha

ORCID: 0000-0001-8404-1261.

E-mail: leandro.o.rocha@hotmail.com

Márcio Cardoso Coelho

ORCID: 0000-0003-2578-6719.

E-mail: coelhocardosomarcio@gmail.com

Fabiano Bossle

ORCID: 0000-0002-9048-6109.

E-mail: fabiano.bossle@ufrgs.br 